\title{
Article \\ Deformations of Subway Tunnels Induced by the Overcrossing Jacked Box Tunnels
}

\author{
Wei Liu, Yinlong Wu, Huajing Zhao, Xiangyang $\mathrm{Xu} * \mathbb{D}$ and Lingyi Miao \\ School of Rail Transportation, Soochow University, Suzhou 215000, China; ggoulmmeng@suda.edu.cn (W.L.); \\ 20194246014@stu.suda.edu.cn (Y.W.); zhao_huajing@suda.edu.cn (H.Z.); 1947406042@stu.suda.edu.cn (L.M.) \\ * Correspondence: X.Y.Xu@suda.edu.cn
}

Citation: Liu, W.; Wu, Y.; Zhao, H.; $\mathrm{Xu}, \mathrm{X}$; Miao, L. Deformations of Subway Tunnels Induced by the Overcrossing Jacked Box Tunnels. Symmetry 2021, 13, 1800. https:// doi.org/10.3390/sym 13101800

Academic Editor: Theodore E. Simos

Received: 7 September 2021

Accepted: 23 September 2021

Published: 27 September 2021

Publisher's Note: MDPI stays neutral with regard to jurisdictional claims in published maps and institutional affiliations.

Copyright: (c) 2021 by the authors. Licensee MDPI, Basel, Switzerland. This article is an open access article distributed under the terms and conditions of the Creative Commons Attribution (CC BY) license (https:// creativecommons.org/licenses/by/ $4.0 /)$.

\begin{abstract}
The rectangular utility tunnels have been increasingly built in urban areas in recent decades In this paper, a case of jacked box tunnels built closely over-crossing the existing subway tunnels in Suzhou, China, is presented. The tunneling-induced deformation of the subway tunnels is measured and analyzed. The measurement indicates that the subway tunnels are uplifted and subjected to the overcrossing box tunneling. As compared, the longitudinal deformation of the range that locates under the box tunnels is more significant than that outside the range. The tunneling-induced deformation of the left subway tunnel is relatively higher than that of the right one. The numerical simulation is performed for validation. The numerical result is agreed with the in-situ measurements. Moreover, the simulation reveals that the presence of friction in jacked tunnels causes the extra uplift deformation of subway tunnels. The higher the friction, the is the deformation. It is affirmed that using the effective lubrication not only facilitates the tunnel jacking but also inabilities the tunneling-induced deformation of underlying tunnels
\end{abstract}

Keywords: jacked box tunneling; overcrossing; deformation; in-situ measurement; numerical simulation

\section{Introduction}

In recent years, there has been a rapid development of underground construction in China. Rectangular tunnels with high space utilization have been gradually used for building urban utility tunnels. As one of the typical trenchless techniques, jacking box tunneling is widely adapted for underground construction. The excavation in box tunneling triggers the significant release of soil stress, i.e., more than that in circular tunnels [1,2]. The inappropriate support on the working face causes unexpected great ground movement and, even worse, a collapse or blowout failure [3-9]. The interaction between the jacked linings and the surrounding soils also impacts the soil movement. The disturbance on the existing underground structures when the jacked box tunnel passing by is complicated. Usually, the unexpected excessive deformation is risky and causes potential problems, such as leakage and structure failure. It is of significance to investigate the tunneling-induced deformation of existing tunnels when the jacked tunneling crossed by.

Many research works have been conducted regarding the impact of jack box tunneling on the surrounding environment. Analytical solutions are a widely used method to analyze the influence on the surface deformation [7-9]. Xu et al. [10] employed Mindlin's solution [11] to analyze the soil deformation caused by additional stress and friction on the excavation surface, and the random medium theory is applied to analyze the soil deformation caused by water and soil loss. Combining Mindlin's and Sagaseta's methods [10,12], Ren et al. [13] presented a three-dimensional analytical solution of ground deformation induced by pipe jacking. Zhang et al. [14] studied the response of roadway and subway tunnel to pipe jacking construction through three-dimensional numerical simulation. Ma et al. [15] discussed the influence of construction sequence on the existing structure by numerical simulation. Lavasan a et al. [16] found that different backfill grouting simulation methods have little impact on the axial force of lining whereas the longitudinal stiffness of 
the existing tunnel lining is one of the major factors affecting the deformation. Liao [17] improved the traditional equivalent stiffness model by considering the influence range of the circumferential seam. Anastasopoulos et al. [18] established a three-dimensional refined joint model for a tunnel under deep water condition in the meizo-seismal area; Wu et al. $[19,20]$ proposed that the longitudinal deformation of tunnel can be categorized as bending and dislocation, and established the calculation formula of equivalent bending stiffness. Yu et al. [21,22] deduced the analytical solution of the longitudinal bending stiffness of segment lining under different conditions. For the numerical simulation, many optimization methods have been tried on the equivalent zone [23-25]. Liu et al. [26] analyzed the vertical displacement, horizontal displacement and radial convergence under the influence of jacking construction. Milligan et al. [27] combined the theoretical model of pipe-soil interaction with field measurement, indicating that friction has a great impact on the surface during pipe jacking construction. Chen et al. [28] proposed that the final surface settlement is positively correlated with the construction sequence based on the comparative results of numerical simulation and on-site measurement in the engineering practice of the first jacked box tunnel in Wuhan, China.

This paper aims to study the influence of the jacked box tunneling on the deformation of the existing subway tunnels. A case of jacked box tunneling overcrossing subway tunnels in Suzhou, China is presented. The in-situ measurement has been carried out and the tunneling-induced deformation of subway tunnels is analyzed. The numerical simulation performed in the environment of ABAQUS is employed for validation. In the simulation, the jacking tunneling is modelled using displacement control method and the interaction between the jacked linings and surrounding soils are considered. The influence of the friction on the tunneling-induced deformation of subway tunnels is discussed.

\section{Project Overview}

Figure 1 shows the parallel rectangular utility tunnels built in Suzhou, China. Each tunnel is about $72 \mathrm{~m}$ long and has the cross-section with the outside width (W) of $6.9 \mathrm{~m}$ and height $(\mathrm{H})$ of $4.2 \mathrm{~m}$. The alignments of the tunnels incline to horizontal at $2.7 \%$ and the buried depths are about $4.1 \mathrm{~m}$. The distance between the box tunnels is $1.5 \mathrm{~m}$. The box tunnels are built using the jacked method, and a rectangular earth pressure balanced boring machine is used for excavation. The uniform prefabricated linings whose lengths of $1.5 \mathrm{~m}$ and thickness of $0.45 \mathrm{~m}$ are used for installation. The utility tunnels are built overcrossing, and parallel to, the subway tunnels. The distance between the alignments of the twin tunnels is $13.1 \mathrm{~m}$. The angles between the alignments of box tunnels and subway tunnels are $70^{\circ}$.

In Figure 2, the subsurface soils consist of $2 \mathrm{~m}$ thick (1) miscellaneous fill, underlain with natural soils deposited with interlayer of (3) 1 clay, (3) 2 silty clay, (4) 3 silty sand, (4)3a silt, and silty (4) 5 clay. The groundwater table is $1 \mathrm{~m}$ below the ground surface. The soil properties are listed in Table 1 The box tunnels are driven in layers (3) 1 and the subway tunnels are mainly buried in layer (4)3a. The distance from the bottom of box tunnels to the crown of subway tunnels is about $2.77 \mathrm{~m}$. The subway tunnels have the same cross-sections. The individual tunnel has its outside diameter of $6.2 \mathrm{~m}$. The C50 concrete segmental linings are installed with M30 bolts in stagger pattern. Each piece is $0.35 \mathrm{~m}$ thick and $1.2 \mathrm{~m}$ wide. 


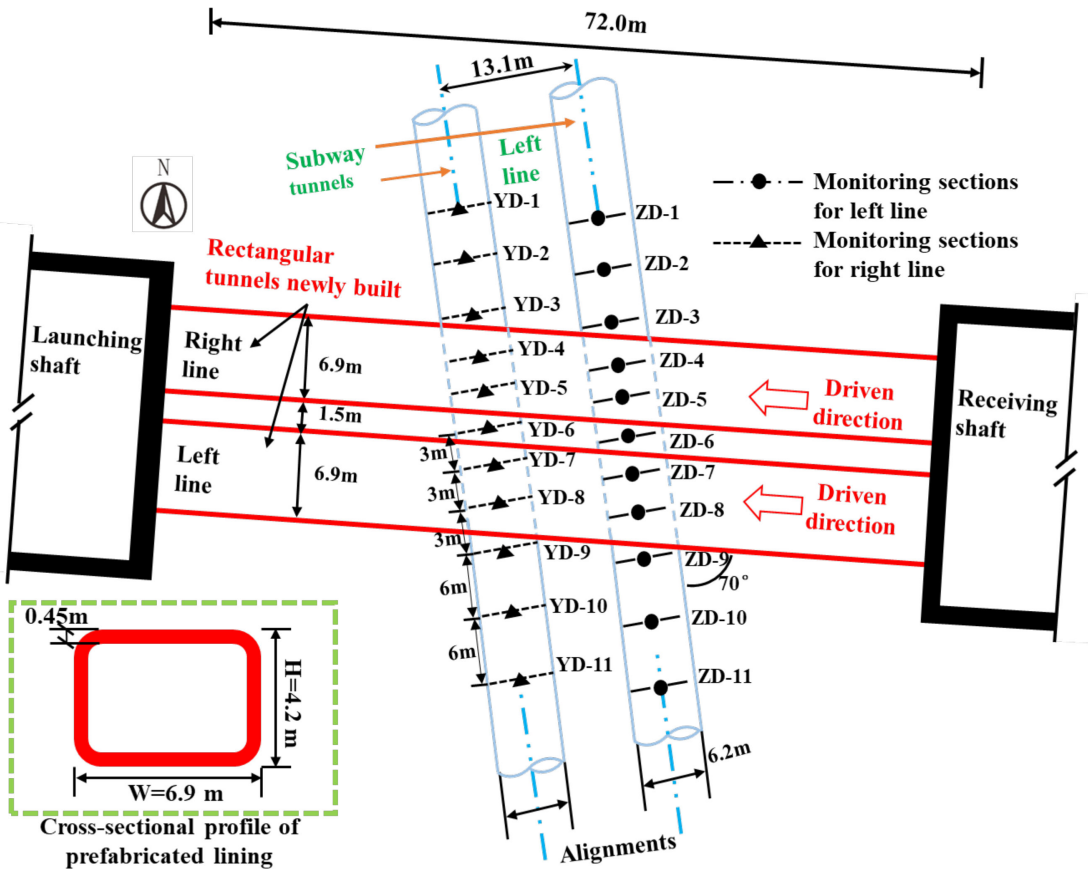

Figure 1. The plan view of the jacked box tunneling project.

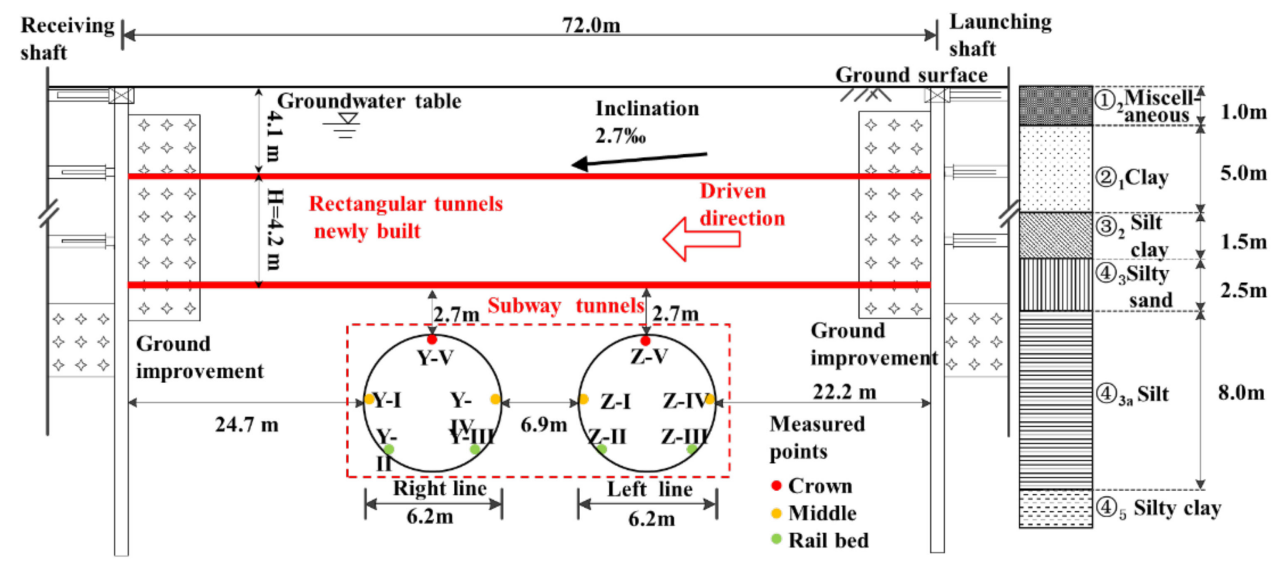

Figure 2. Longitudinal profile of jacked box tunneling.

Table 1. Soil properties.

\begin{tabular}{|c|c|c|c|c|c|c|}
\hline Layers & Soil Type & $\begin{array}{c}\text { Thickness } \\
\text { H/m }\end{array}$ & $\begin{array}{l}\text { Unit Weight } \gamma \\
\qquad / \mathrm{KN} / \mathrm{m}^{3}\end{array}$ & $\begin{array}{l}\text { Compressive } \\
\text { Modulus } \\
\text { Es/MPa }\end{array}$ & $\begin{array}{c}\text { Cohesion } \\
\mathrm{C}_{\mathrm{cq}} / \mathrm{kPa}\end{array}$ & $\begin{array}{l}\text { Frictional Angle } \\
\qquad \varphi_{\mathrm{cq}} /^{\circ}\end{array}$ \\
\hline (1) 2 & $\begin{array}{l}\text { Miscellaneous } \\
\text { fill }\end{array}$ & 1.0 & 19.6 & 5.2 & 20.0 & 12.0 \\
\hline (2) 1 & Clay & 5.0 & 19.0 & 6.3 & 44.5 & 11.0 \\
\hline (3) 2 & Silty clay & 1.5 & 19.3 & 7.2 & 23.4 & 12.9 \\
\hline (4) 3 & Silty sand & 2.5 & 18.9 & 16.8 & 5.2 & 31.1 \\
\hline (4) $3 a$ & Silt & 8.0 & 19.2 & 14.2 & 3.7 & 31.9 \\
\hline (4) 5 & Silty clay & 32.0 & 18.9 & 5.1 & 15.6 & 14.0 \\
\hline
\end{tabular}

\section{In-Situ Measurement}

In Figure 1, for each subway tunnel 11 monitoring sections are set along the longitudinal direction for deformation measurement. The sections marked from ZD-1 to ZD-11 
are for at the left tunnel, while the sections from YD-1 to YD-11 are for the right tunnel. For the right tunnel, the sections YD-4 to YD-8 located below the box tunnels are placed at average distance of $3 \mathrm{~m}$ while the other section is placed at the distance of $6 \mathrm{~m}$. The similar arrangement of the sections is planned for the left tunnel. As shown in Figure 2, for each monitoring section, the vertical displacements at the crown and rail bed, and the horizontal convergence, are measured.

\subsection{Longitudinal Deformations}

Figure 3 shows the vertical displacements of subway tunnels along the longitudinal direction induced by the left-box tunneling. For the left subway tunnel, along the longitudinal direction, the vertical displacements increase the distance to the box tunnel decreases. The largest displacement is measured at section ZD-6 which is located below the box tunnel bottom. In this section, the displacements at the rail bed are higher than that of the crown, indicating a vertical convergence. Along the underlying tunnel, the vertical displacements of the part under the box tunnel bottom are more significant than the rest part. It identifies that, along the subway tunnel longitudinal direction, the influence range is approximately $6.9 \mathrm{~m}$, which equals the width (W) of box. The vertical displacements of the right subway tunnel are less significant than those of the left tunnel, which implies that the left-box tunneling impacts more profoundly on the left subway tunnel than on the right one. The largest vertical displacement of the right subway tunnel is measured at section YD-7, which is also located right below the box tunnel bottom.

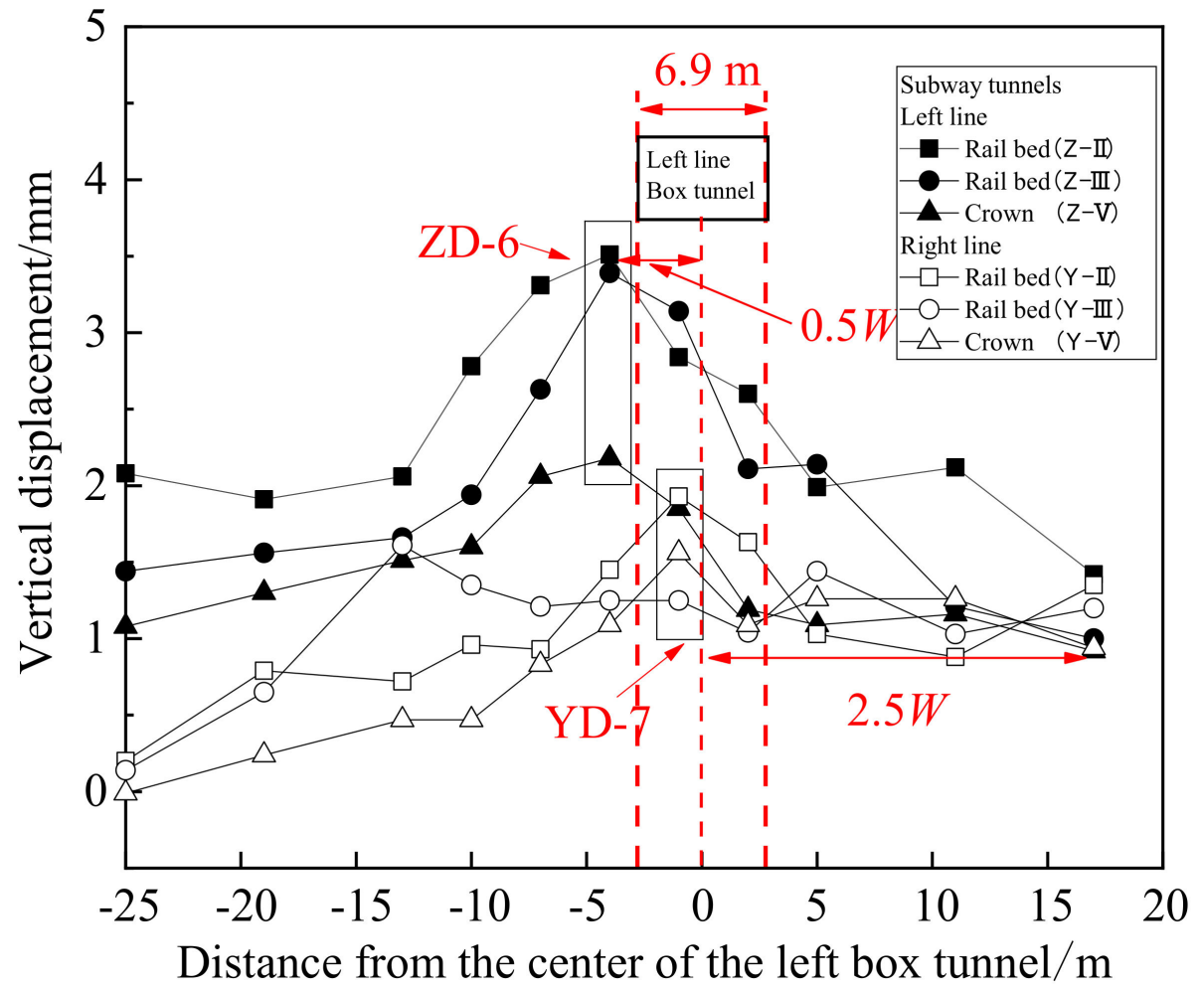

Figure 3. Subway tunnel vertical displacement along the longitudinal direction (left-box tunneling).

Figure 4 shows the accumulated vertical displacement of subway tunnels induced by the right-box tunneling. It can be found that the vertical displacements sections below the right-box tunnel increase more than those at other sections. A more significant influence of right-box tunneling is probably attributed to the stoppage of box tunneling machine for maintenance that causes higher stress release. As compared, the box tunneling-induced uplift deformation of the left subway tunnel is more significant than that of the right subway tunnel. The maximum and minimum values of vertical displacements of subway 
tunnels are summarized in Table 2. For the subway tunnels, the maximum values of vertical displacements are at the sections located under the box tunnels bottoms, while the minimum values of vertical displacements are at the sections located far from the bottoms of the box tunnels.

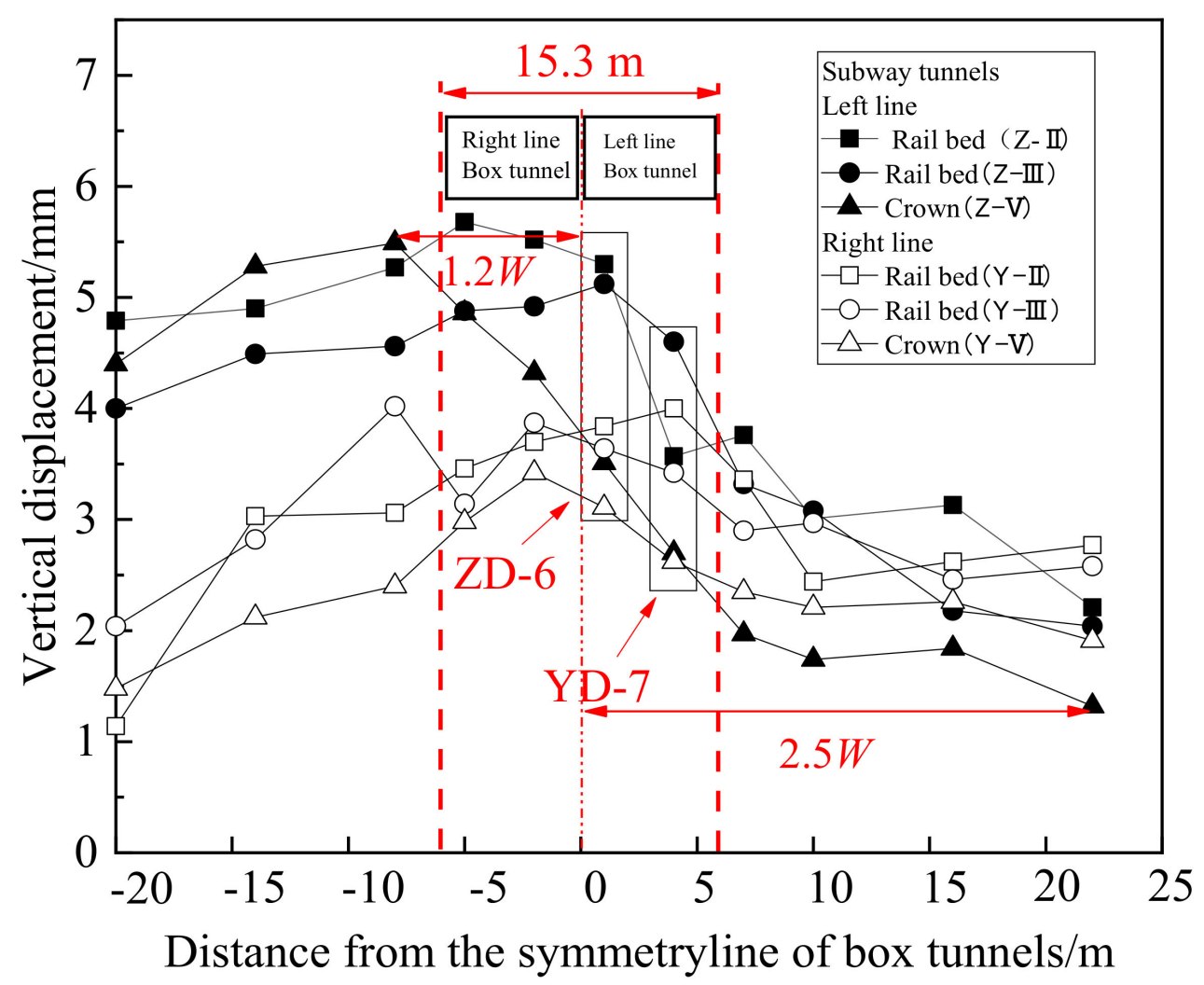

Figure 4. Subway tunnel vertical displacement along the longitudinal direction (right-box tunneling).

Table 2. Maximum and minimum values of vertical displacements of subway tunnels.

\begin{tabular}{cccccc}
\hline \multirow{2}{*}{} & & \multicolumn{2}{c}{ Left Line } & \multicolumn{2}{c}{ Right Line } \\
\cline { 3 - 6 } & & Maximum & Minimum & Maximum & Minimum \\
\hline \multirow{3}{*}{ Crown } & Sections & ZD-3 & ZD-11 & YD-5 & YD-1 \\
& Points & Z-V & Z-V & Y-V & Y-V \\
& Values & $5.49 \mathrm{~mm}$ & $1.32 \mathrm{~mm}$ & $3.42 \mathrm{~mm}$ & $1.48 \mathrm{~mm}$ \\
\hline \multirow{3}{*}{ Rail bed } & Sections & ZD-4 & ZD-11 & YD-7 & YD-1 \\
& Points & Z-II & Z-II & Y-II & Y-II \\
& Values & $5.64 \mathrm{~mm}$ & $1.48 \mathrm{~mm}$ & $4.01 \mathrm{~mm}$ & $1.07 \mathrm{~mm}$ \\
\hline
\end{tabular}

Figure 5 shows the evolution of vertical displacements at the typical section ZD-6 and YD-7 induced by the left-box tunneling. It can be found that, as the left-box tunnel is driven over crossed, the vertical displacements undergo a three-phase variation. In phase I, the vertical displacement virtually keep constant as the box boring machine moves forward, and the box tunneling barely impacts the deformations of the subway tunnels. In phase II, the vertical displacement starts to gradually increase as the box tunneling machine moves succeed $20 \mathrm{~m}$ (from $-12 \mathrm{~m}$ to $15 \mathrm{~m}$ ). During this period, the vertical displacement of rail bed (Z-III) increases from $0.64 \mathrm{~mm}$ to $2.65 \mathrm{~mm}$, i.e., by $2.01 \mathrm{~mm}$ while that of the crown increases from $0.45 \mathrm{~mm}$ to $1.1 \mathrm{~mm}$. In phase III, the vertical displacement slightly increases as the box tunneling machine moves away and the increasing rate is also reduced. It can be noticed that almost 50 percent of the vertical displacement is accumulated during phase II when the box tunneling machine moves from $-10 \mathrm{~m}$ to $10 \mathrm{~m}$. It can be identified that, 
along the box tunnel alignment, the scope from $-10 \mathrm{~m}$ to $10 \mathrm{~m}$ is impacted by the box tunneling. In Figure 5b, the similar variation of vertical displacements at section YD-7 (the right subway tunnel) can be seen. Most of vertical displacements are accumulated during phase II. This founding is consistent with that found in the left tunnel. The increase in vertical displacement at YD-7 is less significant than that at ZD-6.

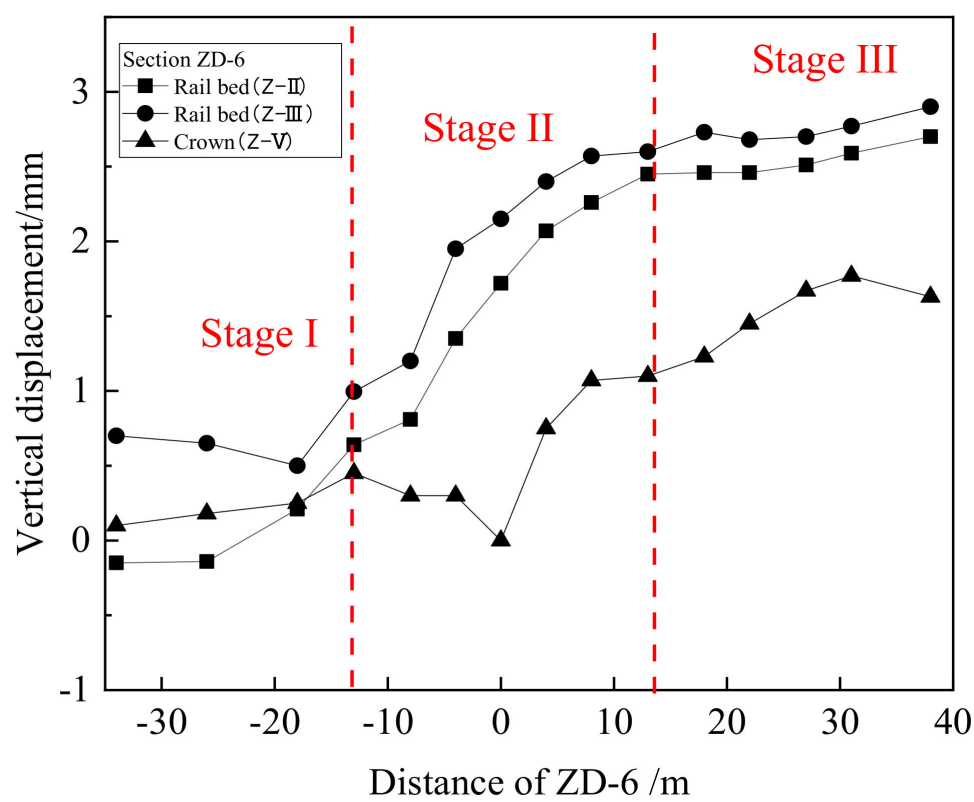

(a) Section ZD-6

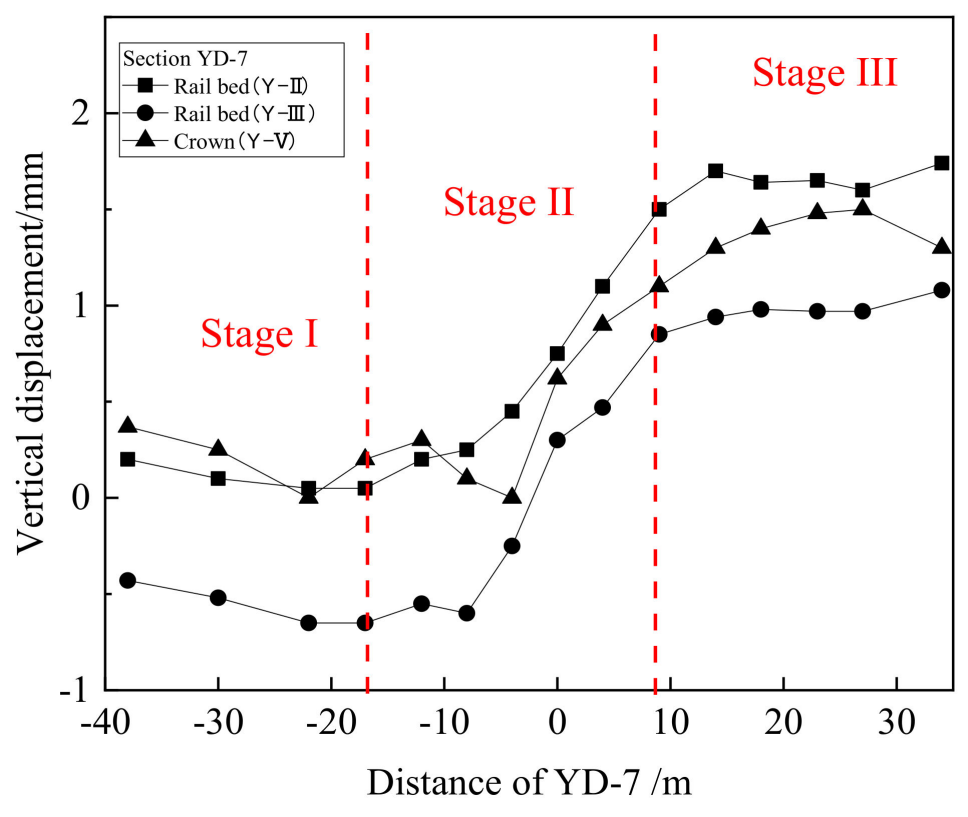

(b) Section YD-7

Figure 5. Variations of vertical displacements corresponding to the box tunneling. 


\subsection{Cross-Sectional Deformations}

The horizontal convergences at typical sections ZD-6 and YD-7 are listed in Table 3. At section ZD-6, the horizontal convergence reaches $0.2 \mathrm{~mm}$ when the left-box tunneling completed, and increases to $0.5 \mathrm{~mm}$ when the right-box tunneling completed. At section YD7 , the convergence induced by the left-box tunneling is $0.8 \mathrm{~mm}$ and it slightly rises to $0.9 \mathrm{~mm}$ when the right-box tunneling completed. As compared, the right-box tunneling causes a more significant change on convergence at section ZD-6. This might be attributed to the temporary stoppage of box tunneling machine for maintenance right above section ZD-6.

Table 3. The convergence of subway tunnels (ZD-6, YD-7).

\begin{tabular}{ccccc}
\hline Sections & Measure Points & Left-Box Tunneling & Right-Box Tunneling & Threshold [29] \\
\hline \multirow{2}{*}{ ZD-6 } & Point (Z-I) & $-0.1 \mathrm{~mm}$ & $-0.2 \mathrm{~mm}$ & \\
& Point (Z-IV) & $0.1 \mathrm{~mm}$ & $0.3 \mathrm{~mm}$ & $\leq 3.1 \mathrm{~cm}$ \\
\multirow{2}{*}{ YD-7 } & Convergence & $0.2 \mathrm{~mm}$ & $0.5 \mathrm{~mm}$ & \\
& Point (Y-I) & $-0.7 \mathrm{~mm}$ & $-0.8 \mathrm{~mm}$ & $\leq 3.1 \mathrm{~cm}$ \\
\hline
\end{tabular}

Figure 6 shows the cross-sectional deformations at section ZD-6 and YD-7. $\Delta_{1}$ and $\Delta_{2}$ are the horizontal displacements, respectively, at points Z-I and Z-IV, induced by the leftbox tunneling. While, $\Delta_{3}$ and $\Delta_{4}$ are the horizontal displacements, respectively, at points Y-I and Y-IV by the right-box tunneling. It can be found that the deformations are elliptical, but not symmetrical, and that the overcrossing box tunneling enlarges the deformations.

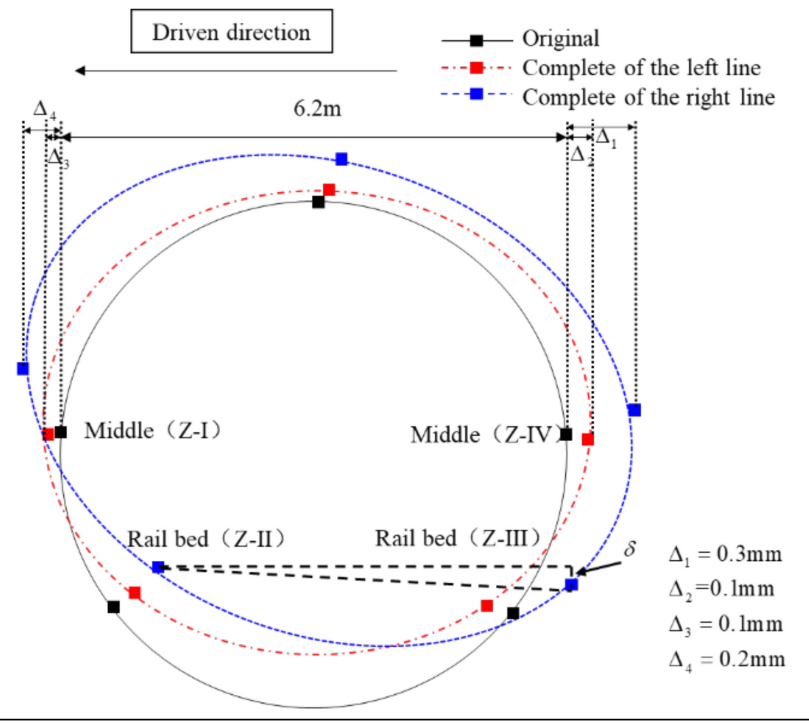

(a) section ZD-6



(b) section YD-7

Figure 6. Cross-sectional deformations.

Table 4 shows the variations of uneven settlements of the rail beds at the typical sections ZD-6 and YD-7. It can be found that the box tunneling increases the uneven settlements of rail beds in the underlying subway tunnels. The overcrossing box tunneling causes more significant uneven settlement in the left subway tunnel than that in the right one. The ultimate rail bed uneven settlement at section is $-0.71 \mathrm{~mm}$ at section ZD-6 while the settlement is $-0.42 \mathrm{~mm}$ at section YD-7. This is consistent with the former finding that the box tunneling-induced deformation of the left subway tunnel is larger than that of the right one. Moreover, induced by the right-box tunneling, the change in uneven settlement at section YD-6 is higher than that subjected to the left-box tunneling. This is because the stoppage of tunneling machine above this section triggers higher stress release. 
Table 4. Uneven settlements of the rail beds in the subway tunnels.

\begin{tabular}{cccccc}
\hline Sections & Rail Bed & Before Tunneling & $\begin{array}{c}\text { Left } \\
\text { Box Tunneling }\end{array}$ & $\begin{array}{c}\text { Right } \\
\text { Box Tunneling }\end{array}$ & Threshold [29] \\
\hline \multirow{2}{*}{ ZD-6 } & Point (Z-II) & $1.01 \mathrm{~mm}$ & $3.43 \mathrm{~mm}$ & $5.31 \mathrm{~mm}$ \\
& Point (Z-III) & $0.75 \mathrm{~mm}$ & $2.77 \mathrm{~mm}$ & $4.60 \mathrm{~mm}$ & $\leq 3.2 \mathrm{~mm}$ \\
\hline \multirow{2}{*}{ YD-7 } & Uneven settlement & $-0.25 \mathrm{~mm}$ & $-0.66 \mathrm{~mm}$ & $-0.71 \mathrm{~mm}$ & $3.84 \mathrm{~mm}$ \\
& Point (Y-II) & $-0.17 \mathrm{~mm}$ & $1.92 \mathrm{~mm}$ & $3.42 \mathrm{~mm}$ & $\leq 3.2 \mathrm{~mm}$ \\
\hline
\end{tabular}

\section{Numerical Simulation}

\subsection{Numerical Modelling}

In this section, the commercial code ABAQUS (2020 version) is employed for the simulation. The numerical model is shown in Figure 7. The dimensions of the model are $60 \mathrm{~m} \times 45 \mathrm{~m} \times 50 \mathrm{~m}$. A work station equipped with a 2.9-GHz quad-core CPU and 32-GB memory is applied for the simulations. By meshing, the numerical model is discretized into the finite elements comprising 39,420 solid elements for the soil masses, 5000 solid elements for box linings, and 2376 structural elements for the subway tunnels. The solid elements (C3D10) are adapted for the soil mass modelling. The soil is regarded as a Mohr-Coulomb material with non-associated rule. The soil dilatancy is not taken into account. The soil properties are listed in Table 1. The solid elements (C3D8) are used for modelling the prefabricated linings of jacked box tunnels. The prefabricated linings are regarded as an elastic material and the properties of the linings are listed in Table 5. The joints between the successive linings are not considered. The individual lining has the constant length of $1.5 \mathrm{~m}$. The installation of 48 pieces of box linings for individual tunnel is performed in the simulation. The interaction between box linings and surrounding soils are modelling by activating the function of surface contact. For the interface, the hard contact is used to describe the normal behavior. The tangential behavior is governed by the frictional coefficient. The damping is not considered. The jacked tunneling is simulated by applying the uniform displacement of $1.5 \mathrm{~m}$ (the length of each box lining) along the longitudinal direction over the nodes of the lining element [30]. The box tunneling-induced ground loss is considered in the simulation and the modelling is performed by altering the mechanical parameters of the influence zone. The elastic constitutive model is adapted for the modelling. According to the previous research [31-33], the average thickness of the zone is chosen as $0.3 \mathrm{~m}$, the unit weight of the material is $20 \mathrm{kN} / \mathrm{m}^{3}$, the elastic modulus is 2.0 $\mathrm{MPa}$, and the passion ratio is 0.2 .

Table 5. Parameters for the numerical model of box lining.

\begin{tabular}{ccccc}
\hline & Elastic Modulus & Passion Ratio & Density & Thickness \\
\hline Box lining & $3350 \mathrm{MPa}$ & 0.17 & $2400 \mathrm{~kg} / \mathrm{m}^{3}$ & $0.45 \mathrm{~m}$ \\
\hline
\end{tabular}

The lings of the subway tunnels are modelled using shell element (SR4), one of structural elements. The relative motion between soil and linings is not considered. The model of cylindrical shell within elastic foundation [17] is used for segmental lining modelling. The model equivalent bending longitudinal stiffness $(E I)_{\mathrm{eq}}$ is calculated by

$$
(E I)_{\mathrm{eq}}=\eta E_{S} I_{S}
$$

where $\eta$ is the reduction factor of tunnel stiffness, $E_{S} I_{S}$ is the bending stiffness of concrete segment.

Ratio $\eta$ is calculated by

$$
\eta=K_{f} /\left(K_{f}+\alpha_{f}\right)
$$


where $K_{f}$ is the rotation stiffness coefficient of circumferential joint, and $\alpha_{f}$ is the influence of factor for circumferential joints.

The coefficient $K_{f}$ is determined by

$$
K_{f}=\frac{\cos ^{3} \psi}{\cos \psi+(\pi / 2+\psi) \sin \psi}
$$

where $\psi$ is angle of neutral axis.

The factor $\alpha_{f}$ is calculated by $\alpha_{f}=l_{f} / l_{b}$, where $l_{f}$ is the influence length of circumferential joint and $l_{b}$ is the length of each ring. The empirical $\alpha_{f}=0.5$ suggested by Huang et al. [30] is adapted for modelling.

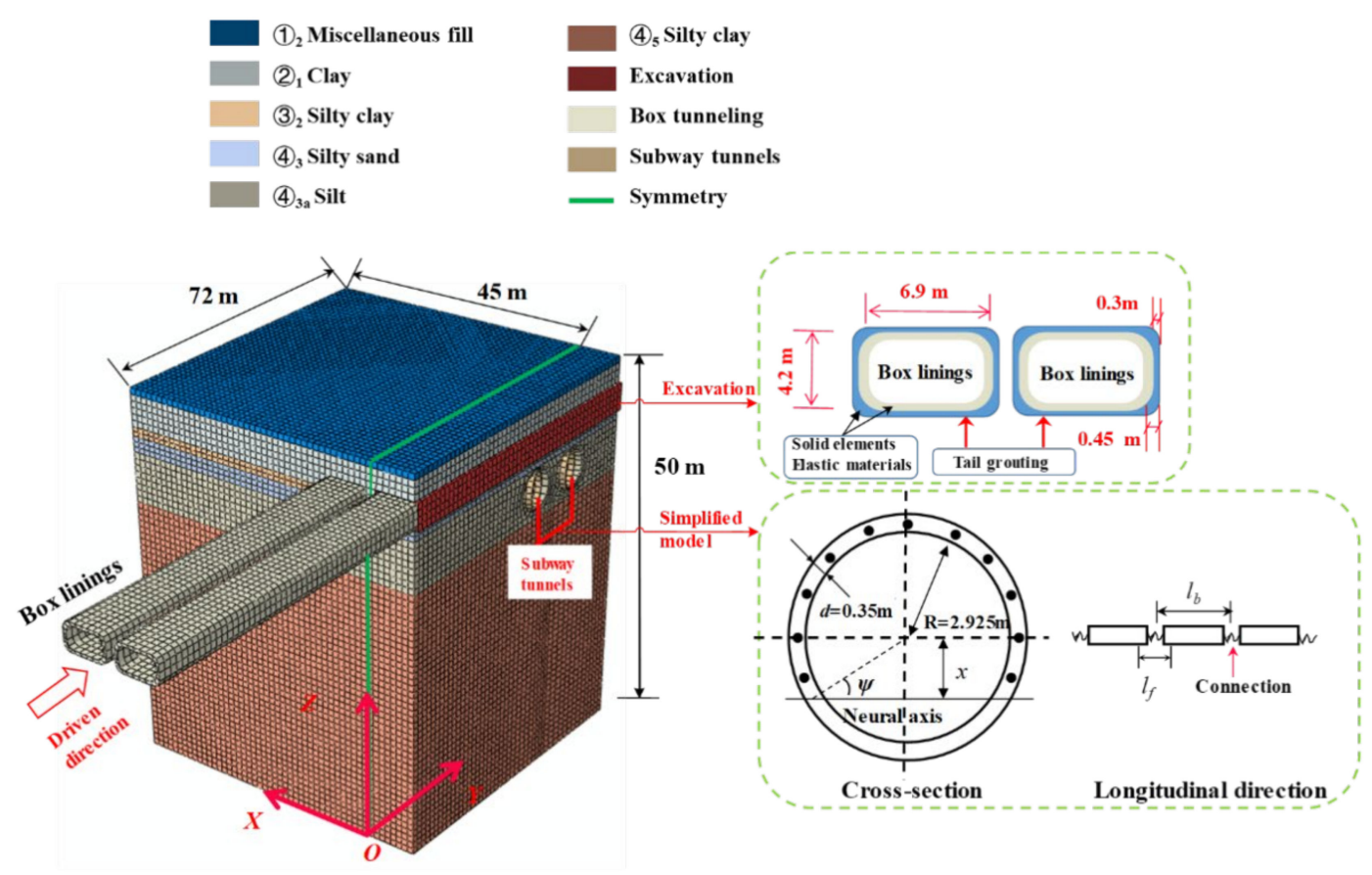

Figure 7. Numerical modelling.

In this simulation, this equivalent model is adapted for modelling the subway tunnels. The segmental linings of the subway tunnels are installed by assembling the concrete segments with steel bolts. Sixteen bolts are adapted for each lining and the bolt has an average length of $600 \mathrm{~mm}$, a diameter of $30 \mathrm{~mm}$, and an elastic modulus of $206 \mathrm{GPa}$. Referred to Equation (1), the ratio is obtained as 0.243 . The parameters of subway tunnels for simulation are listed in Table 6. By bonding the nodes of structural elements of subway tunnels to adjacent soil elements, the relative motion between soil and linings is not considered so that the friction is neglected.

Table 6. Parameters for structural elements of subway tunnels.

\begin{tabular}{ccccccc}
\hline & Elastic Modulus & Passion Ratio & Reduction Ratio & Thickness & Interface \\
\hline Subway tunnels & $3350 \mathrm{MPa}$ & 0.15 & 0.243 & $0.35 \mathrm{~m}$ & None \\
\hline
\end{tabular}

Figure 8 illustrates the simulation process. The subway tunnel structures and the initial stress field are activated by sequence. The initial stress field is generated based on the concept of total stress. Along the depth, the distribution of vertical earth stress $\sigma_{v}$ is governed by the traditional earth pressure theorem of which $\sigma_{v}$ is the product of soil weight and depth. The horizontal earth stress is governed by $K_{0} \sigma_{v}$, where $K_{0}$ is the at-rest earth pressure coefficient. Before the simulation on box tunneling, the displacement field 
is forced to zero. The box tunneling simulation includes the following steps: (1) using "killing elements" to fulfill 1.5-m-long excavation; (2) activating the influence zone and the interface between the zone and box linings; (3) assigning the element nodes of box linings with a 1.5-m displacement along the $y$-axis; and (4) running the simulation until convergence. The process is then repeated for jacking each box lining until the whole simulation is accomplished.

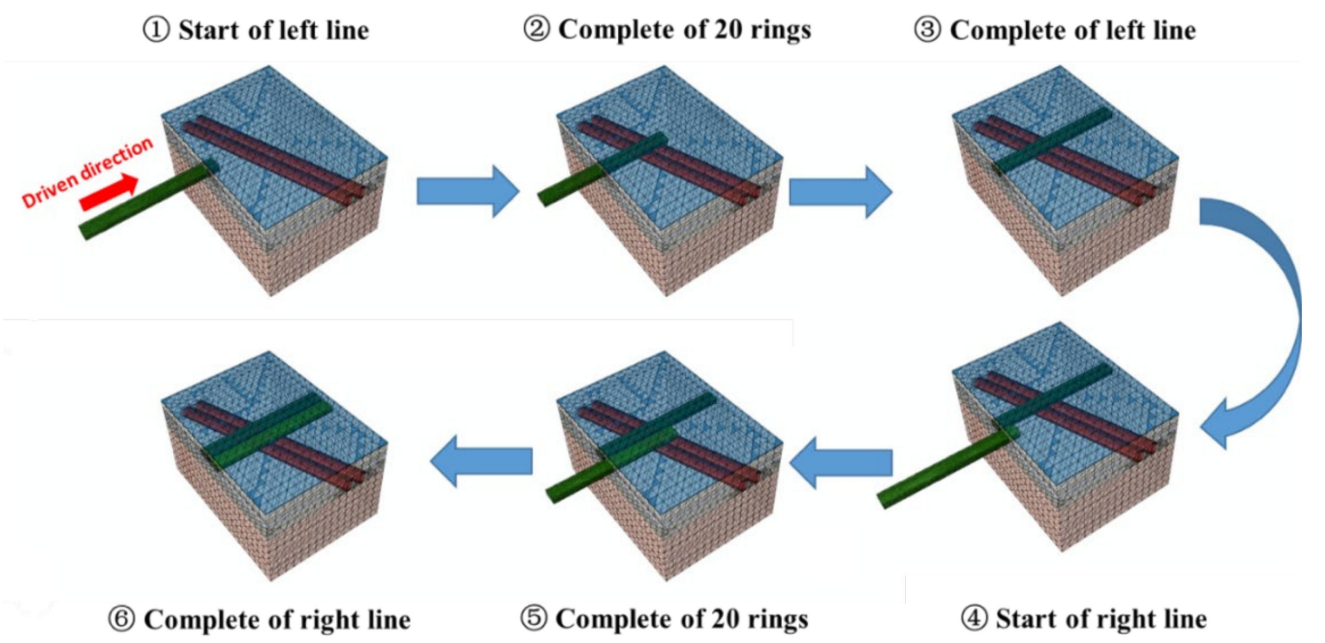

Figure 8. The numerical simulation process.

\subsection{Numerical Results}

\subsubsection{Validation}

Figure 9 shows the comparisons on the longitudinal deformation of the right subway tunnels. It can be found that the numerical simulation agrees with the measurement. It notices that, when the right-box tunneling is complete, the measured largest displacement is located under the bottom of right-box tunnel while, in the simulation, the largest one is located at the symmetry plan. This is because, in the simulation, the stoppage of the right-box tunneling is not considered.

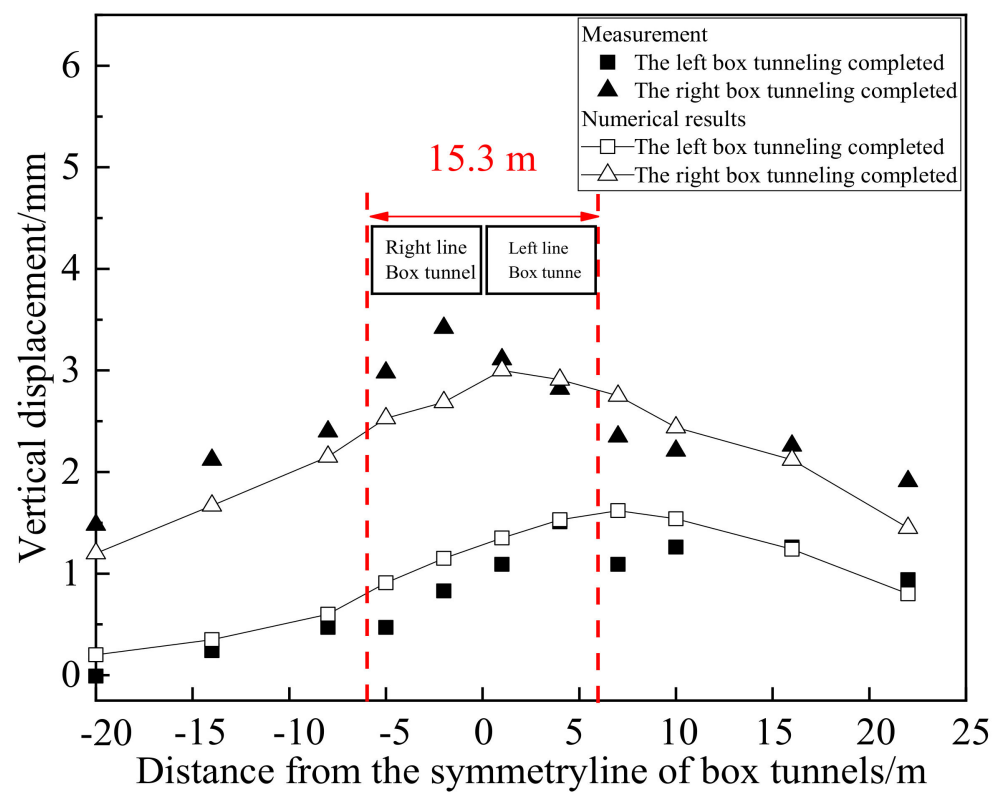

Figure 9. Comparisons on the longitudinal deformation of the right subway tunnels. 


\subsubsection{Influence of Friction on Subway Tunnel Deformations}

The influence of friction on the subway tunnel deformations is investigated by varying coefficient $\mu$ from 0 to 1 at interval of 0.25 . Figure 10 shows the left-box tunneling-induced subway tunnel deformations. It can be found that the longitudinal deformations vary in the similar pattern at different at different $\mu$. At constant $\mu$, the left-box tunneling-induced deformation of the left subway tunnel is larger than that of the right subway tunnel. For subway tunnels, the longitudinal deformations became more significant with increasing $\mu$. For example, the largest deformation of the left subway tunnel is $2.0 \mathrm{~mm}$ at $\mu=0$ and changes to $2.5 \mathrm{~mm}$ at $\mu=1$, and the largest deformation of the right subway tunnel is $0.0 .9 \mathrm{~mm}$ at $\mu=0$ which then increases to $1.5 \mathrm{~mm}$ at $\mu=1$.



Figure 10. Longitudinal deformations induced by the left-box tunneling at different $\mu$.

Figure 11 shows the accumulated longitudinal deformations when the right-box tunneling completed. It can be found that, for both subway tunnels, the higher the friction $\mu$, the more significant the deformation. Compared with Figure 10, the right-box tunnelinginduced deformation of the left subway tunnel is also larger than that of the right subway tunnel. At different $\mu$, the subway tunnels deform in the similar pattern along the longitudinal direction. This indicates that the friction impacts on the deformation magnitude more significantly than on the deforming pattern.

Figure 12 shows the influence of friction on the maximum vertical displacement of the underlying tunnels. It can be found that the vertical displacement increases with increasing $\mu$. For the left-box tunneling, the tunneling-induced vertical displacement of left underlying tunnel increases from $2.01 \mathrm{~mm}$ to $2.64 \mathrm{~mm}$, while that of right underlying tunnel increases from $1.25 \mathrm{~mm}$ to $1.73 \mathrm{~mm}$ as $\mu$ varies from 0 to 1 . This result indicates that the presence of friction between box linings and the surrounding soil triggers the extra uplift movement. It implies that, in box tunneling, facilitating the lubrication that reduces the friction is able to inhabit the uplift movement of the underlying tunnels. 


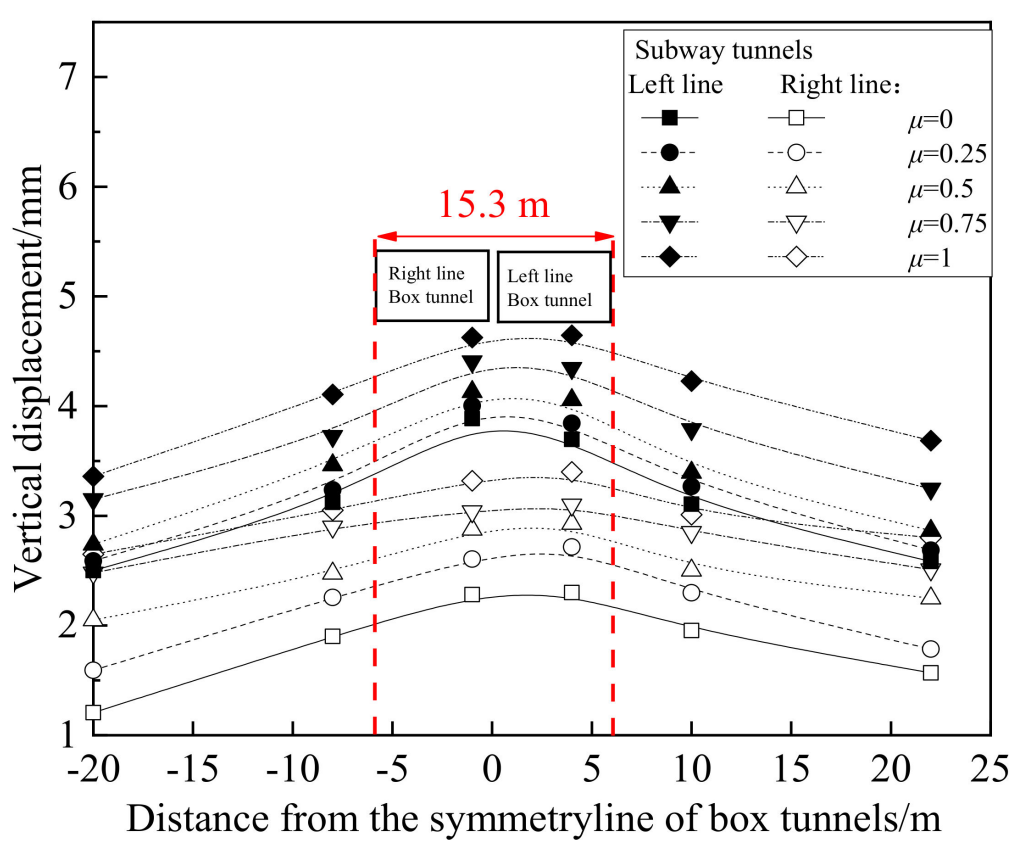

Figure 11. Accumulated longitudinal deformations of underlying tunnels.

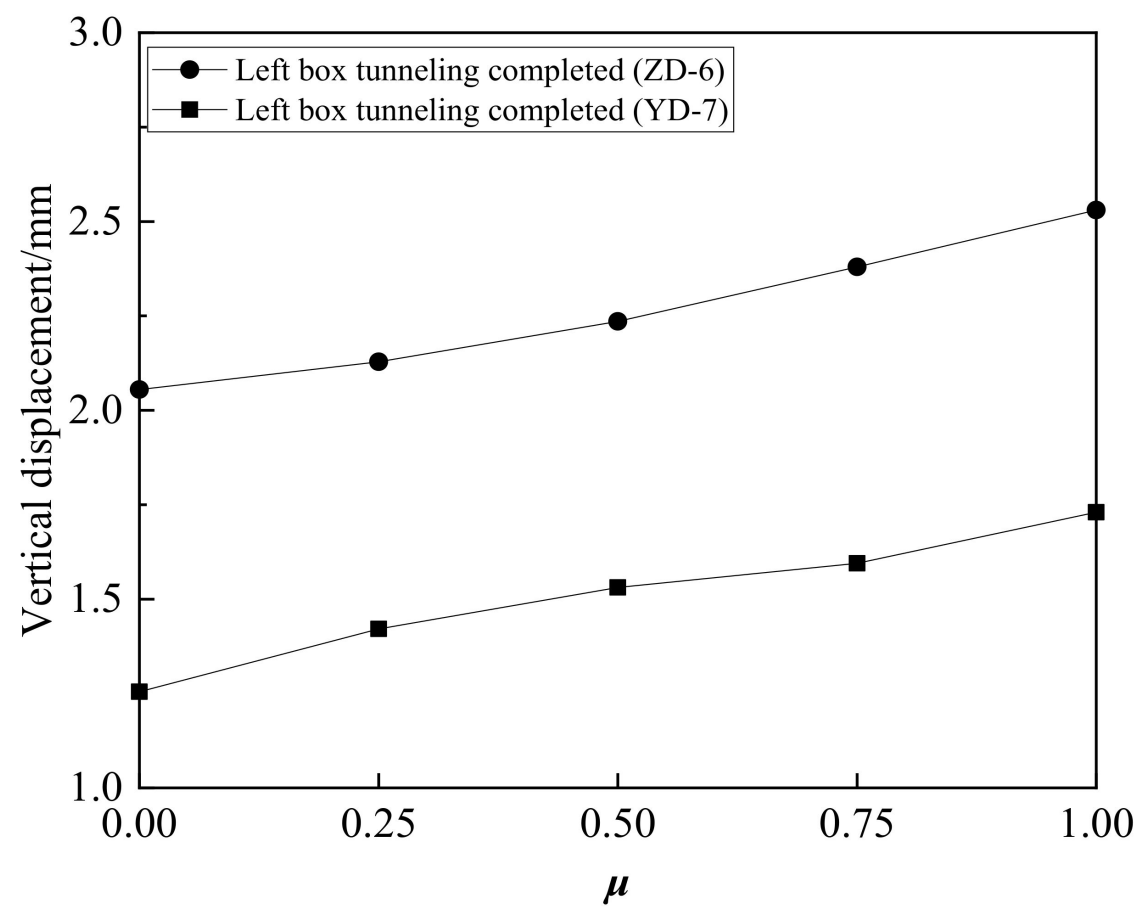

Figure 12. Influence of friction on the maximum displacement.

\section{Conclusions}

In the paper, the deformations of subway tunnels induced by overcrossing jacked box tunneling are investigated. The in-situ measurements show that overcrossing box tunneling triggers the upwards movement of subway tunnels. For the subway tunnels, the longitudinal deformation below the bottom of box tunnels is more significant than that outside the range. In this range, the cross-sectional deformation is elliptical. The influence of the overcrossing tunneling becomes more significant when it approaches the subway tunnels. The deformation of subway tunnels reaches the peak as the jacked box tunneling over-crosses above the subway tunnels. Over 50 percent of the deformation is accumulated 
during the period when the box tunneling machine is in the range of $\pm 10 \mathrm{~m}$ from the tunnel. Outside this range, the influence of the box tunneling could be neglected. Similarly, the right-box tunneling causes more significant uplift deformation than the left one because its stoppage above the left subway tunnel causes higher stress release.

The numerical simulation is employed for validation. The box tunneling via jacking method is simulated, in which the interaction between the jacked tunnel and surrounding soil are fully considered. The numerical results are agreed with the in-situ measurement. Moreover, the influence of the friction on the tunneling-induced deformations of subway tunnels is analyzed. The higher the friction, the more significant the deformations of subway tunnels. For the left line, the longitudinal deformation increases by $25 \%$ when the frictional coefficient increases from 0 to 1 . The influence of friction is more significant on the deformation of the right subway tunnel. The result indicates the significance of reducing the friction between the jacked tunnel and surrounding soils by enhancing the lubrication in jacked box tunneling.

Author Contributions: Conceptualization, methodology, writing—original draft, W.L.; Investigation; validation, Y.W.; Formal analysis, writing—reviewing and editing, H.Z.; Supervision, X.X.; Investigation; software, L.M. All authors have read and agreed to the published version of the manuscript.

Funding: This research is supported by the National Natural Science Foundation of China (Grant Nos. 51978430).

Institutional Review Board Statement: Not applicable.

Informed Consent Statement: Not applicable.

Data Availability Statement: Not applicable.

Conflicts of Interest: The authors declare no conflict of interest.

\section{References}

1. Islam, M.S.; Iskander, M. Twin tunnelling induced ground settlements: A review. Tunn. Undergr. Space Technol. 2021, 110, 103614. [CrossRef]

2. Chen, R.P.; Zhu, J.; Liu, W.; Tang, X.W. Ground movement induced by parallel EPB tunnels in silty soils. Tunn. Undergr. Space Technol. 2011, 26, 163-171. [CrossRef]

3. Leca, E.; Dormieux, L. Upper bound and lower bound solutions for the face stability of shallow circular tunnels in frictional material. Géotechnique 1990, 40, 581-606. [CrossRef]

4. Mollon, G.; Dias, D.; Soubra, A.H. Face stability analysis of circular tunnels driven by a pressurized shield. J. Geotech. Geo-Environ. Eng. 2010, 136, 215-229. [CrossRef]

5. Liu, W.; Zhao, Y.; Shi, P.; Li, J.; Gan, P. Face stability analysis of shield-driven tunnels shallowly buried in dry sand using 1-g large-scale model tests. Acta Geotech. 2017, 13, 693-705. [CrossRef]

6. Liu, W.; Wu, B.; Shi, P.; Xu, X. Analysis on face stability of rectangular cross-sectional shield tunneling based on an improved two-dimensional rotational mechanism. Acta Geotech. 2021, 1-14. [CrossRef]

7. Li, X.-Y.; Liu, G.-B. A Complex Variable Solution for Rectangle Pipe Jacking in Elastic Half-Plane. Math. Probl. Eng. 2017, 2017, 5713063. [CrossRef]

8. Zhang, X.; Chen, J.; Bai, Y.; Chen, A.; Huang, D.Z. Ground surface deformation induced by quasi-rectangle EPB shield tunneling. J. Zhejiang Univ. Eng. Sci. 2018, 52, 317-324. [CrossRef]

9. Zhao, W.; Jia, P.; Zhu, L.; Cheng, C.; Han, J.; Chen, Y.; Wang, Z. Analysis of the Additional Stress and Ground Settlement Induced by the Construction of Double-O-Tube Shield Tunnels in Sandy Soils. Appl. Sci. 2019, 9, 1399. [CrossRef]

10. Xu, Y.J.; Wang, Y.J.; Feng, C.; Liu, Z.W.; Zhu, J. Research on ground deformation caused by rectangular pipe jacking construction. Chin. J. Undergr. Space Eng. 2018, 14, 192-199. (In Chinese)

11. Mindlin, R.D. Force at a point in the interior of a semi-infinite solid. Physics 1936, 7, 195-202. [CrossRef]

12. Sagaseta, C. Analysis of undrained soil deformation due to ground loss. Geotechnique 1987, 37, 301-320. [CrossRef]

13. Ren, D.-J.; Xu, Y.-S.; Shen, J.S.; Zhou, A.; Arulrajah, A. Prediction of Ground Deformation during Pipe-Jacking Considering Multiple Factors. Appl. Sci. 2018, 8, 1051. [CrossRef]

14. Zhang, D.; Liu, B.; Qin, Y. Construction of a large-section long pedestrian underpass using pipe jacking in muddy silty clay: A case study. Tunn. Undergr. Space Technol. 2016, 60, 151-164. [CrossRef]

15. Ma, P.; Shimada, H.; Sasaoka, T.; Hamanaka, A.; Dintwe, T.K.M.; Pan, D. Investigation on the Performance of Pipe Roof Method Adjacent to the Underground Construction. Geotech. Geol. Eng. 2021, 39, 4677-4687. [CrossRef] 
16. Lavasan, A.A.; Zhao, C.; Barciaga, T.; Schaufler, A.; Steeb, H.; Schanz, T. Numerical investigation of tunneling in saturated soil: The role of construction and operation periods. Acta Geotech. 2017, 13, 671-691. [CrossRef]

17. Liao, S.-M.; Peng, F.-L.; Shen, S.-L. Analysis of shearing effect on tunnel induced by load transfer along longitudinal direction. Tunn. Undergr. Space Technol. 2008, 23, 421-430. [CrossRef]

18. Anastasopoulos, I.; Gerolymos, N.; Drosos, V.; Kourkoulis, R.; Georgarakos, T.; Gazetas, G. Nonlinear Response of Deep Immersed Tunnel to Strong Seismic Shaking. J. Geotech. Geoenviron. Eng. 2007, 133, 1067-1090. [CrossRef]

19. Wu, H.-N.; Shen, S.-L.; Liao, S.-M.; Yin, Z.-Y. Longitudinal structural modelling of shield tunnels considering shearing dislocation between segmental rings. Tunn. Undergr. Space Technol. 2015, 50, 317-323. [CrossRef]

20. Wu, H.-N.; Shen, S.-L.; Yang, J.; Zhou, A. Soil-tunnel interaction modelling for shield tunnels considering shearing dislocation in longitudinal joints. Tunn. Undergr. Space Technol. 2018, 78, 168-177. [CrossRef]

21. Yu, H.; Cai, C.; Bobet, A.; Zhao, X.; Yuan, Y. Analytical solution for longitudinal bending stiffness of shield tunnels. Tunn. Undergr. Space Technol. 2019, 83, 27-34. [CrossRef]

22. Yu, H.; Zhang, Z.; Chen, J.; Bobet, A.; Zhao, M.; Yuan, Y. Analytical solution for longitudinal seismic response of tunnel liners with sharp stiffness transition. Tunn. Undergr. Space Technol. 2018, 77, 103-114. [CrossRef]

23. Zhang, Y.; Yin, Z.Z.; XU, Y.F. Analysis of three-dimensional ground surface deformations due to shield tunnel. Chin. J. Rock Mech. Eng. 2002, 21, 388-392. (In Chinese)

24. Fei, Y.E.; Mao, J.H.; Ming, J.I.; Wang, C.; Sun, C.; Chen, Z. Research status and development trend of back-filled grouting of shield tunnels. Tunn. Constr. 2015, 35, 739-752. (In Chinese)

25. Lin, H.; Wu, W.B.; Wang, C.; Feng, K.; Tan, R.; Dai, Z. Study of Soil Chamber Grouting Technology for EPB Shield in Water-rich Weathered Rock with Large Depth. Tunn. Constr. 2018, 38 (Suppl. 2), 268-277. (In Chinese)

26. Liu, B.; Zhang, D.; Fang, L. Structural Response of Existed Metro Tunnels to Adjacent Large-section Pipe Jacking Construction. Procedia Eng. 2017, 189, 11-17. [CrossRef]

27. Milligan, G.W.E.; Norris, P. Pipe-soil interaction during pipe jacking. Proc. Inst. Civ. Eng. Geotech. Eng. 1999, 137, 27-44. [CrossRef]

28. Chen, C.; Zheng, X.D.; Chen, Y.X.; Wang, C.; Zhong, S.; He, B. Construction monitoring and numerical simulation analysis of the first metro entrance/exit tunnel constructed by rectangular pipe jacking method in Wuhan. Tunn. Constr. 2013, 33, 354-361. (In Chinese)

29. Ministry of Housing and Urban-Rural Department of People's Republic of China. Code for design and building foundation (GB50157-2013). In National Standard of the People's Republic of China; China Architecture and Building Press: Beijing, China, 2013.

30. Huang, H.; Xu, L.; Yan, J. The longitudinal model test of shield tunnel. Tunn. Undergr. Space Technol. 2006, 21, 418-419. [CrossRef]

31. Yen, J.; Shou, K. Numerical simulation for the estimation the jacking force of rectangular jacked box tunneling. Tunn. Undergr. Space Technol. 2015, 49, 218-229. [CrossRef]

32. Zheng, G.; Lu, P.; Diao, Y. Advance speed-based parametric study of greenfield deformation induced by EPBM tunneling in soft ground. Comput. Geotech. 2015, 65, 220-232. [CrossRef]

33. Xie, X.; Yang, Y.; Ji, M. Analysis of ground surface settlement induced by the construction of a large-diameter shield-driven tunnel in Shanghai, China. Tunn. Undergr. Space Technol. 2016, 51, 120-132. [CrossRef] 